\title{
Selection of optimal modes of obtaining broad fractions of light hydrocarbons from oil-associated gas at oil production sites
}

\author{
Aleksei LIPANOV ${ }^{1}$, Andrei LESCHEV ${ }^{2}$, Pavel OVCHARENKO', Daynier Rolando \\ DELGADO SOBRINO ${ }^{3 *}$, Lyudmila KOLESNIKOVA ${ }^{4}$ and Konstantin STERKHOV
}

Authors' affiliations and addresses:

${ }^{1}$ Keldysh Institute of Applied Mathematics,

Russian Academy of Sciences (RAS),

Russia, Moscow, Miusskaya Sq., 4,

e-mail: am135@yandex.ru

${ }^{2}$ Udmurt Federal Research Center, UrD, RAS, Russia, Udmurt Republic, Izhevsk, T.

Baramzina St., 34,

e-mail: 1130758@yandex.ru

e-mail: ovcpg@yandex.ru

${ }^{3}$ Institute of Production Technologies, Faculty of Materials Science and Technology in

Trnava, Slovak University of Technology in Bratislava, Jána Bottu 25, 917 24, Slovakia tel: + 421908674132 ,

e-mail: daynier_sobrino@stuba.sk

${ }^{4}$ Kalashnikov Izhevsk State Technical

University, Russia, Udmurt Republic, Izhevsk,

Studencheskaya St., 7

e-mail: klusian@yandex.ru

e-mail: skvdw@mail.ru

*Correspondence:

Daynier Rolando DELGADO SOBRINO, Institute of Production Technologies, Faculty of Materials Science and Technology in Trnava, Slovak University of Technology in Bratislava, Jána Bottu 25, 917 24, Slovakia tel: + 421908674132

e-mail: daynier_sobrino@stuba.sk

How to cite this article:

Lipanov, A., Leschev, A., Ovcharenko, P., Delgado Sobrino, D.R., Kolesnikova, L. and Sterkhov, K. (2020). Selection of optimal modes of obtaining broad fractions of light hydrocarbons from oil-associated gas at oil production sites. Acta Montanistica Slovaca Volume 25 (1), 1-13

DOI:

https://doi.org/10.46544/AMS.v25i1.1

\begin{abstract}
Decreasing pollution and increasing oil fields profitability are key goals of the proper extraction of hydrocarbons from oil-associated gas (OAG). Despite the potential of a proper OAG utilization, oil companies often struggle with an increase in the overall gas cost and possible unprofitability of its treatment though conventional methods (Igitkhanyan et al., 2014). These cost-related issues have been mentioned before by authors like Braginskii and Chernavskiito (2011) and Arutyunov et al. (2017). This paper introduces a novel method for OAG separation and the subsequent obtention of the Broad Fraction of Light Hydrocarbons (BFLH) that relies on compression followed by the cooling. The proposal is implemented on a mobile laboratory unit developed to define power expenditures and optimize the modes of obtaining broad fractions of hydrocarbons from $\mathrm{OAG}$ at oil fields with low gas factor and caloricity due to high nitrogen content. The experiments of the paper contributed validating the proposed method and the mobile unit, and this, among others, by determining optimal modes for the obtention of the BFLH from AOG with different initial compositions of hydrocarbons components and harmful admixtures, and also by determining concrete values for the dependence of the OAG compression pressure on temperature.
\end{abstract}

\section{Keywords}

Oil-associated gas, compression, broad fractions, light hydrocarbons, mobile laboratory unit, oil fields

(C) 2020 by the authors. Submitted for possible open access publication under the terms and conditions of the Creative Commons Attribution (CC BY) license (http://creativecommons.org/licenses/by/4.0/). 


\section{Introduction and Background Information}

During the process of extraction, delivery and processing of oil, the OAG is produced. The OAG is a natural hydrocarbon gas diluted in oil or being in the "caps" of oil and gas-condensate fields. The amount of OAG in one ton of oil can vary from one, two up to several thousand cubic meters (Semenova et al., 2016; Ivanova et al., 2018). In contrast to natural gas, OAG contains, apart from methane and ethane, a large share of propane, butane and heavier hydrocarbons (RIA Novosti). One of the main and subsequent procedures of OAG utilization lies on its splitting into separate components. This treatment process allows obtaining dry stripped gas and a broad fraction of light hydrocarbons (BFLH). This BFLH can be further used as raw material for petrochemical productions, as ecologically pure fuel for heating, used in the same oil preparation process chain right at the oil filed, and there are even recent studies analyzing its theoretical use for power generation in gas-piston engines thus significantly decreasing its flaring (Arutyunov et al., 2020).

World volumes of OAG extracted together with oil are rather significant (Baranov et al., 2017). Half a century ago OAG was just burnt at flare facilities, thus doing significant harm to ecology and this because when burning OAG, carbon dioxide and active soot are released into the atmosphere. Today, however, even where there are still other pollution problems associated to oil and gas production, see Atoufi and Lampert (2020), this associated product of oil extraction, i.e. OAG, is more frequently caught and used, among others, for heating technical premises and producing electrical power. This is an approach that allows industrial enterprises to solve their own power problems without needing power supply from outside what in many cases leads to cost savings if the gas is obtained efficiently and properly (Škvareková et al., 2019). Besides, OAG is also a valuable raw material for the chemical industry. This altogether allows, not only to qualitatively utilize OAG preserving the ecology but also to obtain profit from it in petrochemistry.

Over the last years, the main problem of OAG has been widely discussed all over the globe, including Russia. In Russia, especially after the governmental decrees on increasing the payment for limit-excessing burning of OAG came into effect and after the activation of investment programs of oil-and-gas companies, the qualitative changes in this sphere have started to occur. Thus, the recent and expected production growth of light hydrocarbon raw material in Russia for further use in the petrochemical industry is directly connected with OAG processing growth (Kiryushin et al., 2013).

Oil-associated gas can be both a valuable and dangerous associated component during oil extraction. Usually, there is no constant ratio of OAG components, and thus there can be a completely different proportion of OAG components at different oil fields. The OAG contains the following components: methane (CH4), ethane $(\mathrm{C} 2 \mathrm{H} 6)$, propane $(\mathrm{C} 3 \mathrm{H} 8)$, butane $(\mathrm{C} 4 \mathrm{H} 10)$, pentane $(\mathrm{C} 5 \mathrm{H} 12)$, hexane $(\mathrm{C} 6 \mathrm{H} 14)$, carbon dioxide $(\mathrm{CO} 2)$, nitrogen (N2), oxygen (O2) and hydrogen sulfide (H2S) (GOST R 55598), Kuppusamy et al. (2020). These components can be conventionally divided into foamy - hydrocarbons (methane, ethane, propane, butane, pentane, hexane), inert (hydrogen, carbon dioxide), and harmful or dangerous - hydrogen sulfide, carbon dioxide. The content of hydrocarbons at different oil fields varies in a very broad range. Thus, at some oil fields OAG can contain over $80 \%$ of hydrocarbons, while at others, usually old ones, the content of hydrocarbons does not exceed 6 or 7 $\%$ (Speight, 2012; Kayukova et al., 2009).

Generally, OAG extracted from wells is unstable by its component composition and volume. As mentioned, at different oil fields usually OAG with different compositions will be extracted. Even in fields located close to each other, the OAG composition can significantly differ. Besides, the gas composition also changes with the field depletion. In this particular case, inert components, such as, first of all, nitrogen, prevail in the OAG composition. Similarly, the volume of extracted OAG depends on the good recovery given that with the increase in the oil field operation time, both the oil and OAG volume extraction usually goes down. In turn, OAG hydrocarbons can be divided as follows:

- gas - components of group C1, C2 (methane, ethane) being only in a gaseous state under the conditions close to atmospheric ones (pressure and temperature). They are slightly diluted in liquids;

- unstable components of group C3, C4 (propane, butane) - gases, become liquids at low temperature or under elevated pressure (1.6 MPa);

- $\quad$ and stable C5, C6 (pentane, hexane).

Gas components are distinguished by the fact that they are converted into the liquid state at very low temperatures or under very high pressures. Unstable hydrocarbons can be in a gaseous state at normal temperature, and in a liquid state under the pressure of $0.16 \mathrm{MPa}$. On the other hand, stable hydrocarbons are liquids.

As for the use of the gases, these can be used only either at the extraction site or transported by a gas pipeline transport which has been preliminarily prepared, i.e. dried and purified. On the other hand, in liquid state OAG components can be used either on-site or transported by automobile transport. Components in a liquid state can be used as:

- $\quad$ solvents when repairing wells; 
- fuels at oil fields and with insufficient amount of own OAG;

- $\quad$ to return pentane-hexane group into marketable oil.

At the oil fields in the operation of the Russian Udmurt Republic, the extracted oil is characterized by the low gas factor ranging from 4.5 to $35 \mathrm{~m}^{3} / \mathrm{t}$. Besides, OAG here contains a lot of nitrogen - from 30 up to $90 \%$, and consequently, it has low caloricity - from 1200 up to $6600 \mathrm{kcal} / \mathrm{m}^{3}$. Also, at the majority of oil fields in the area OAG contains a significant amount of hydrogen sulfide $0.2-0.5 \%$ (up to $2 \%$ ) by volume, and, consequently, $\mathrm{OAG}$ is practically useless for domestic purposes.

The OAG complexity lies on more careful preparation in contrast to the natural gas. The preparation comprises its separation from heavier hydrocarbons and water. During the phases of transportation and use in pipelines, these components can be condensed and form liquid plugs, and also clogs that leads to damage in the gas equipment (Rafa et al., 2014). The OAG can be transported only by pipeline transport or by its compression. In both cases, it is a quite expensive process. Therefore, while working with small volumes of OAG, it is advisable to use it only for technological purposes at oil fields for oil preparation, namely, for its heating.

One of the main tasks and ways for decreasing environmental pollution and increasing the profitability of oil fields is precisely the extraction of unstable and stable hydrocarbons from OAG. In this case, the liquid fraction can be obtained, which can be transported by mobile means of transportation.

All the existing methods of OAG processing can be split into three main groups: physic-energy; thermalchemical and chemical-catalytic. In this regard, three main technologies have been developed based on these methods: cryogenic technologies (low-temperature separation, condensation, rectification); membrane technology and adsorption technology (Vorobiev et al., 2018). Despite the existence of these well-known methods, in the actual practice of oil fields, only some methods of OAG processing are applied. The main and most used method is usually OAG utilization by its separation into components. This process allows obtaining dry stripped gas which, by its essence, is the same natural gas and also the BFLH. The BFLH can be further used, for example, as raw material for petrochemical productions.

It is well-known in the states of the art and practice, see for example Igitkhanyan et al. (2014) that the most suitable and effective approach of OAG utilization is its treatment at the same gas processing plants. This is explained by the fact that for faraway oil fields, OAG transportation to such utilization plants is very costly, and, in some cases, is either complicated or even impossible from the technical side. In such cases, it is advisable to realize the OAG processing at the same oil fields, which is by far a more profitable option, especially for those cases where the oil field operation time or its life cycle are quite limited.

However, the real difficulties arise when implementing any possible utilization method for the later use OAG for manufacturing or commercial purposes, which are conditioned by the features of this type of raw material, and this, as it is necessary to perform the whole set of works for OAG preparation, i.e. removal of mechanical admixtures and drying, and stripping, desulfurization, laying gas pipelines to distant oil fields, see Karch et al. (2018), construction of gas collecting facilities to just cite the most important ones.

In each particular case, the types and volume of works differ, since they are defined by the same OAG features, distances and conditions of transportation and ultimately by the requirements of the gas consumer. In any case, the fulfilment of any volume of such preparatory measures results in oil gas cost increase and possible unprofitability of OAG treatment for oil companies (Bako and Božek, 2016), what at the end also leads to further negative impact for the environment and a lost chance for the involved companies in the generation of some extra profits.

In this regard and as mentioned above, from the perspective of economic feasibility, it is preferable to treat OAG directly at the oil field obtaining the liquid fraction (BFLH), as liquid BFLH is more convenient and costeffective to transport to chemical enterprises and besides, it can be more effectively used for own purposes as producing heat or electric power, and this because the BFLH has higher caloric value than oil-associated gas (Mullakhmetova et al., 2015).

Based on all described background information, problematic issues and gaps in the states of the art and practice, the present paper introduces a small-sized mobile laboratory unit "LURPNG" for obtaining the BFLH from OAG. The unit has been developed and produced by Izhevsk specialists from UdmFRC UrD RAS together with teachers and students of Kalashnikov Izhevsk State Technical University under the supervision of Academician of RAS, Doctor of Science in Engineering, Prof. A.M. Lipanov. The main goals behind the design and development of this unit have been: 1) to offer the possibility of experimental determination of the BFLH obtention from OAG on certain oil fields and 2) to provide a more flexible BFLH obtention by being able to transport the proposed unit by a wide scale of means of transportation, especially to those oil fields located far from the main transport arteries. The solution of the problem set up addressed with the proposed unit and within the paper is topical for distant oil fields with a low rate, which besides lack gas pipeline systems, thus, the OAG is utilized by burning. 


\section{Material and Methods}

A synthesized description of the proposed laboratory unit for oil-associated gas separation "LURPNG"

The Laboratory unit "LURPNG" is intended for defining power losses and optimizing the modes for obtaining the BFLH from OAG at oil fields with low gas factor and low caloricity due to high nitrogen content, see Fig. 1.

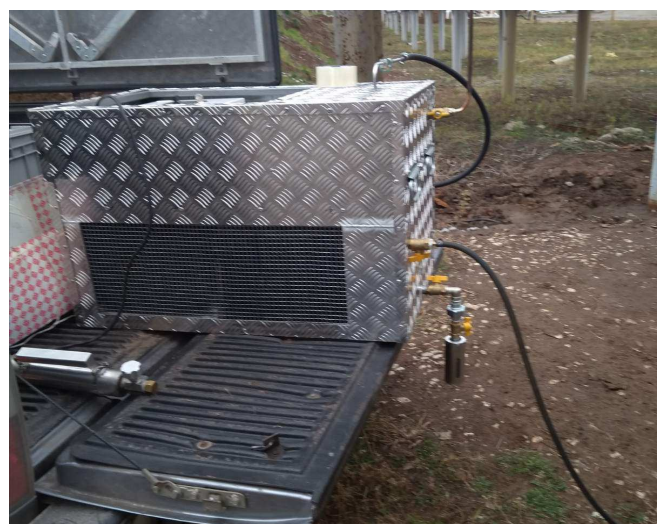

Fig. 1. Laboratory unit for OAG separation “LURPNG. Source: Self-elaboration.

In the particular case of the proposed unit, the compression method of gas mixture separation is used to obtain the BFLH from the OAG (Zaitsev et al., 2017). This laboratory unit is equipped with a refrigeration machine, which allows significantly lowering the costs for the BFLH condensation, thus, making it attractive from the point of power costs. The small unit size allows effectively using it on smaller distant oil fields, specifically the ones with low rate. The technology of compression separation is based on different elasticities of saturated vapours and the difference in condensation pressures of separate components of the mixture. When the temperature or pressure in a two-phase system (vapour - liquid) change, its equilibrium is disrupted and immediately renovated due to the change in the mass ratio of the phases. For example, at a constant temperature, the vapour phase compression results in the condensation of the part of vapours, and with the volume increase, the part of the liquid is evaporated. In both cases, the vapour phase pressure, corresponding to the given temperature, does not change (Lipanov et al., 2016).

However, with the compression method, the extraction degree of heavy hydrocarbons is lower, as only a part of hydrocarbon vapours is condensed, the second part stays in the vapour phase to maintain the phase equilibrium. The transition degree is defined by the initial composition, i.e. by the content of heavy hydrocarbons and pressure elevation degree (Leschev et al., 2009).

The pressure of the gas mixture $\mathrm{p}$ is calculated by the following Eq. 1:

$$
p=\sum_{i=1}^{N} p_{i},
$$

Where:

$p_{i}=x_{i} p-$ the partial pressure of $\mathrm{i}$-gas in the mixture composition;

$\mathrm{N}$ - number of gases in the mixture;

$\mathrm{xi}$ - molar concentration of the i-gas in the mixture.

The bond of the partial pressures, volume and mass of the gas is defined by the following Eq. 2 .

$$
p_{i}=\frac{m_{i}}{\mu_{i}} \cdot \frac{R T}{V}=\mu_{i} \frac{R T}{V}
$$

Where:

$m_{i}$ - mass of the i-gas of the mixture;

$\mu_{i}-$ the molar mass of the i-gas;

$\mathrm{R}$ - gas constant;

$\mathrm{T}$ - the temperature of the gas mixture;

$\mathrm{V}$ - the volume of the gas mixture.

On the other hand, with the OAG compression, the pressure of all its components increases proportionally, and part of the gases, whose pressure exceeded the vapour pressure, is condensed. The Antoine equation (Eq. 3) that appears next can be used to calculate the pressure of saturated vapours of gases in a pressure range up to $0,2-0,3 \mathrm{mPa}$ (Khafizov et al., 2012). 


$$
\ln \left(P_{s}\right)=\frac{A-B}{T+C}
$$

Where:

A, B, C - empirical coefficients (Skaftymov, 2012), T - temperature in K, Ps - saturated vapour pressure in $\mathrm{mm} \mathrm{Hg}$.

The following Tab. 1 displays the pressure data of saturated OAG vapour components depending on the temperature (Blyablyas et al., 2017).

Tab. 1. Saturated OAG vapour components pressure values under different temperatures

\begin{tabular}{|c|c|c|c|c|c|c|}
\hline \multirow{2}{*}{ Substance } & \multirow{2}{*}{$\begin{array}{c}\text { Boiling temperature, } \\
{\left[{ }^{\circ} \mathrm{K}\right]}\end{array}$} & \multicolumn{5}{|c|}{ The pressure of saturated vapour at different temperatures of OAG, $[\mathrm{MPa}]$} \\
\hline & & $253\left[{ }^{\circ} \mathrm{K}\right]$ & $263\left[{ }^{\circ} \mathrm{K}\right]$ & $273\left[{ }^{\circ} \mathrm{K}\right]$ & $283\left[{ }^{\circ} \mathrm{K}\right]$ & $293\left[{ }^{\circ} \mathrm{K}\right]$ \\
\hline Propane & 231.1 & 0.2397 & 0.3387 & 0.4653 & 0.6238 & 0.8180 \\
\hline Isobutane & 261.3 & 0.0711 & 0.1063 & 0.1537 & 0.2158 & 0.2951 \\
\hline n-Butane & 272.7 & 0.0443 & 0.0682 & 0.1013 & 0.1457 & 0.2037 \\
\hline n-Pentane & 309.2 & 0.0088 & 0.0149 & 0.0240 & 0.0371 & 0.0555 \\
\hline n-Hexane & 341.9 & 0.0018 & 0.0034 & 0.0059 & 0.0099 & 0.0159 \\
\hline Hydrogen sulfide & 212.8 & 0.5350 & 0.7433 & 1.0057 & 1.3290 & 1.7200 \\
\hline
\end{tabular}

From Tab. 1, it can be seen that heavier hydrocarbons are condensed under low pressure. It can also be concluded that, in terms of the OAG condensation, as the temperature increases, the pressure of saturated vapours increases as well. Consequently, the expenditures of OAG components condensation go up. In the considered pressure and temperature ranges of Tab. 1, hydrogen sulfide condensation takes place under higher pressure and at a lower temperature. In this regard, it is also possible to come to the conclusion that having selected the optimal pressure and temperature modes during OAG condensation, it is possible to exclude or minimize hydrogen sulfide penetration into the condensate. The optimal selection of such modes is one of the important elements the present paper highlights, and at the same time, something that the proposed method and the mobile unit designed and developed take into account.

Based on these facts and with the aim of practically verify them, the mobile laboratory unit "LURPNG" has been designed, produced and tested at oil fields of the Udmurt Republic and Samara region to solve the problem of optimal mode selection of OAG condensation at particular places of oil extraction with different chemical compositions. The following Fig. 2 shows the block diagram of the developed laboratory unit.

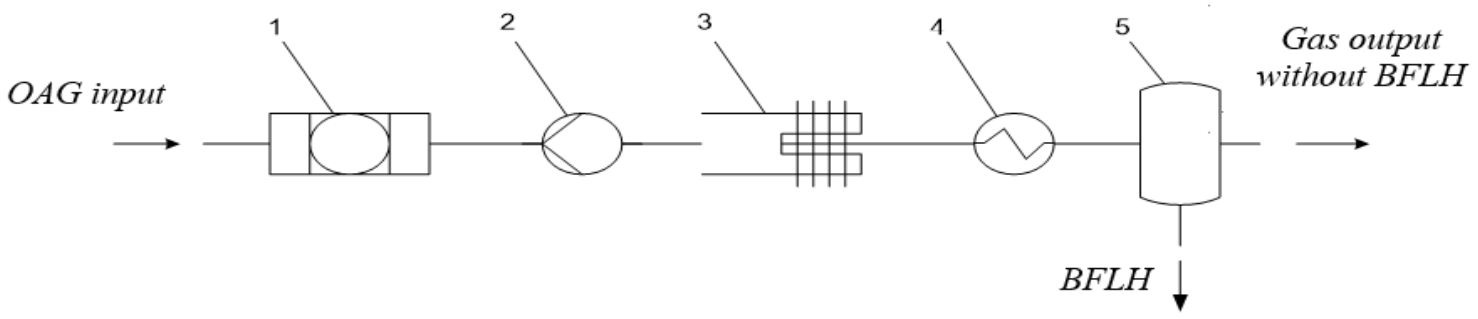

Fig. 2. Block Diagram of the proposed unit. 1 -Filter, 2 -Compressor, 3 -Air heat exchanger, 4 - Evaporator of the refrigeration machine, 5 -Separator. Source: Self-elaboration.

On the other hand, Tab. 2 displays technical characteristics and parameters of the mobile laboratory unit for OAG separation "LURPNG".

Tab. 2. Key technical characteristics and parameters of the unit "LURPNG"

\begin{tabular}{l|c}
\multicolumn{2}{c}{ Tab. 2. Key technical characteristics and parameters of the unit "LURPNG" } \\
\hline Designation & Parameter value \\
\hline Rated capacity of the unit for OAG, $\left[\mathrm{m}^{3} / \mathrm{hr}\right]$ & $2.0-3.0$ \\
Input power, $[\mathrm{kW}]$ & $0.5-1.50$ \\
Control volume of BFLH filling, $\left[\mathrm{ml}^{2} / \mathrm{m}^{3}\right]$ & $100 / 0.0001$ \\
Supply voltage, $[\mathrm{V}]$ & 220 \\
The unit is equipped with sensors & Input gas consumption \\
Maximum weight of the unit, $[\mathrm{kg}]$ & Output gas consumption \\
Overall dimensions $(\mathrm{LxWxH}),[\mathrm{m}]$ & Electrical power consumption \\
\hline
\end{tabular}


As can be seen in Fig. 2, in brief, the general functioning of the laboratory unit for OAG separation starts with its connection to the gas pipe using a high-pressure hose. Inside the unit, the gas gets into the filter (1) where it is cleaned from water and oil drops, then it gets into the gas counter and compressor (2). The heated gas is cooled down to the ambient temperature by the air heat exchanger (3) and then to $40{ }^{\circ} \mathrm{C}$ by the tubular heat exchanger. The heat exchanger is in the refrigeration evaporator chamber (4), where the freon gas from the refrigeration machine is supplied. A controller sets the condensation cooling temperature of the gas products. Subsequently, from the tubular heat exchanger, the gas flows into the separator (5) upper part. The porous body is the centre of the condensate drop formation; the condensate is collected in the same separator lower part. When the ball valves are open, the condensate is collected in a transparent measured sampler for the BFLH connected to same separator 5. The sampler is a 100-ml measuring glass bottle.

On the other hand, the pressure in the separator is set by a membrane valve consisting of two cavities - the lower one connected to the separator, and the upper one connected to the LNG container (Leschev et al., 2009). The liquefied gas in the container is in the equilibrium state, i.e. depending on the temperature, it will be under certain pressure, which defines the condensation of light hydrocarbon vapours, which are in it, and also the heavier ones. In the case of the container being filled with propane, all the gases, including it, are condensed in the separator. All lighter gases, for instance, from hydrocarbons - methane, ethane, from the inert gases nitrogen, inert gases, carbon dioxide, etc. flow through a membrane valve to the atmosphere via the gas meter. The elastic membrane divides two-valve cavities - the upper one, which is a reference with the filled gas, and the lower one which is the working one. When the gas pressure in the working cavity exceeds the pressure in the reference one (condensation pressure, vapour pressure), the membrane bends and the gas flows through holes being subsequently discharged into the atmosphere. When the pressure in the valve working cavity goes down, the membrane closes the holes, and the discharge stops. The pressure in the separator (condensation pressure of the BFLH vapours) is controlled by the manometer. Finally, when the reference volume of the transparent measured vessel is filled, the unit is switched off, the data of the meters are recorded, the ball valves are closed, and the sampler with the BFLH is disconnected from the unit.

The laboratory unit proposed by the authors in this paper has been successfully tested at some oil fields of the Udmurt Republic and Samar region as it will be detailed further in the experimental part of this paper. The main aims have been, among others, to evaluate the possibility of extracting the BFLH from OAG at different oil fields, and to assess the operational efficiency of the mobile laboratory unit "LURPNG" at different oil fields and under different conditions, see Fig. 3. When tested, the laboratory unit has demonstrated itself as workable and simple in operation.

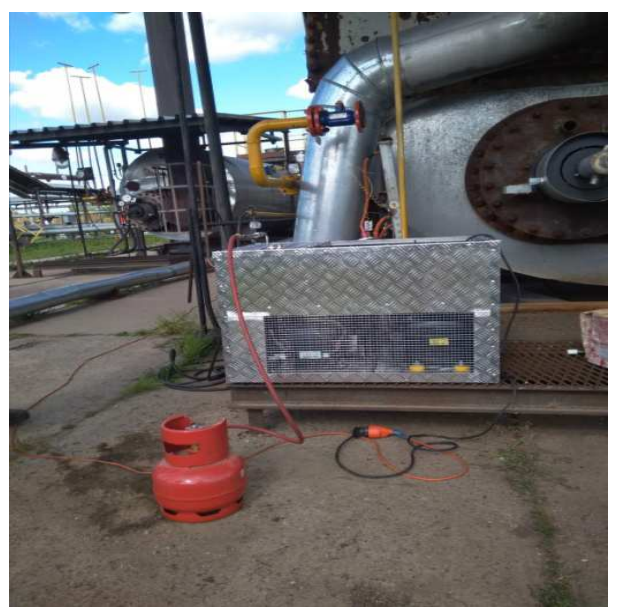

Fig. 3. Testing of the mobile laboratory unit "LURPNG" at an oil filed in the Udmurt Republic. Source: Self-elaboration.

\section{Results and Discussion}

\section{Analysis of the experiment results for obtaining the BFLH from OAG with different chemical compositions.}

The experiment presented here is mainly aimed at defining the optimal condensation temperature, at which the electrical power consumption to obtain the BFLH liquid phase will be minimal. This experiment is realized using the designed and developed mobile laboratory unit "LURPNG based on the compression method. During the experiment, the amounts of input and output gas were measured. The parameters of the input gas (OAG) used to obtain the BFLH are given in Tab. 3 . 
The obtained BFLH was discharged into the transparent measured $100 \mathrm{ml}$ vessel $\left(0.0001 \mathrm{~m}^{3}\right)$; the vessel filling time was measured with a stopwatch. When the transparent vessel was filled up to $100 \mathrm{ml}$, the unit was switched off, and the recordings of the inlet gas volume meters, outlet gas volume meters and electric power meter were taken. The recordings of the gas volume meters were related to normal conditions. For this particular experiment, the normal conditions were assumed as those of a pressure of 101, $325 \mathrm{~Pa}(1 \mathrm{~atm} ., 760 \mathrm{~mm} \mathrm{Hg})$ and a temperature of $293.15 \mathrm{~K}$, i.e. the so-called "room" temperature of $20{ }^{\circ} \mathrm{C}$ (Physical encyclopedia).

Tab. 3. Chemical composition of the input gas $(O A G)$

\begin{tabular}{|c|c|c|c|}
\hline No & Index designation & $\begin{array}{c}\text { Test results, measurement } \\
\text { units [\%] }\end{array}$ & $\begin{array}{l}\text { Extended uncertainty of the test } \\
\text { results }(\mathrm{P}=0.95)[\%]\end{array}$ \\
\hline 1. & Helium molar fraction & 0.088 & \pm 0.008 \\
\hline 2. & Helium volumetric fraction & 0.088 & \pm 0.009 \\
\hline 3. & Hydrogen molar fraction & 0.0262 & \pm 0.0025 \\
\hline 4. & Hydrogen volumetric fraction & 0.0264 & \pm 0.0027 \\
\hline 5. & Oxygen molar fraction & 0.033 & \pm 0.004 \\
\hline 6. & Oxygen volumetric fraction & 0.034 & \pm 0.004 \\
\hline 7. & Nitrogen molar fraction & 54.8 & \pm 1.1 \\
\hline 8. & Nitrogen volumetric fraction & 55.2 & \pm 1.4 \\
\hline 9. & Carbon dioxide molar fraction & 1.36 & \pm 0.11 \\
\hline 10. & Carbon dioxide volumetric fraction & 1.36 & \pm 0.12 \\
\hline 11. & Methane molar fraction & 12.4 & \pm 0.6 \\
\hline 12. & Methane volumetric fraction & 12.5 & \pm 0.7 \\
\hline 13. & Ethane molar fraction & 6.2 & \pm 0.6 \\
\hline 14. & Ethane volumetric fraction & 6.2 & \pm 0.6 \\
\hline 15. & Propane molar fraction & 14.4 & \pm 0.6 \\
\hline 16. & Propane volumetric fraction & 14.3 & \pm 0.7 \\
\hline 17. & i-Butane molar fraction & 2.56 & \pm 0.15 \\
\hline 18. & i-Butane volumetric fraction & 2.51 & \pm 0.16 \\
\hline 19. & n-Butane molar fraction & 5.5 & \pm 0.3 \\
\hline 20. & n-Butane volumetric fraction & 5,3 & $\pm 0,3$ \\
\hline 21. & i-Pentane molar fraction & 1.26 & \pm 0.13 \\
\hline 22. & i-Pentane volumetric fraction & 1.21 & \pm 0.13 \\
\hline 23. & $\mathrm{n}$-Pentane molar fraction & 1.01 & \pm 0.10 \\
\hline 24. & n-Pentane volumetric fraction & 0.96 & \pm 0.10 \\
\hline 25. & Hexane molar fraction & 0.43 & \pm 0.04 \\
\hline 26. & Hexane volumetric fraction & 0.40 & \pm 0.04 \\
\hline 27. & Hydrogen sulfide molar fraction & under 0.01 & - \\
\hline 28. & Hydrogen sulfide volumetric fraction & under 0.01 & - \\
\hline
\end{tabular}

On the other hand, in the previous Tab. 3, it can be seen that OAG contains over $50 \%$ of inert gas nitrogen, this means that the work for condensing this nitrogen is useless, since after the OAG treatment nitrogen is released into the atmosphere. Consequently, the pressure elevation for OAG components condensation is unfeasible.

The unit was tested at the ambient temperature of $+20^{\circ} \mathrm{C}$, and two test samples were taken at different conditions of condensation temperature. The test sample 1 was obtained at the condensation temperature in the separator of $+4^{\circ} \mathrm{C}$, while the test sample 2 was obtained at the temperature of $+20^{\circ} \mathrm{C}$. The selection of the condensation temperature $\left(+4^{\circ} \mathrm{C}\right.$ and $\left.+20^{\circ} \mathrm{C}\right)$ was conditioned by the fact that a condensation temperature below $+4^{\circ} \mathrm{C}$ ice crystals can be formed in the condensate and clog the pipeline, while at high condensation temperature the process proceeds under high pressure, resulting in increased power expenditures (Skaftymov, 2012). The liquefied gas container, setting the condensation pressure in the separator with the membrane valve, was also at the ambient temperature of $+20^{\circ} \mathrm{C}$ when taking test samples 1 and 2 . As a result of the tests, the BFLH liquids with the diluted gases were obtained, see Tab. 4. 
Tab. 4. Component composition and volumetric concentration of the BFLH gas phase

\begin{tabular}{|c|c|c|c|c|c|c|c|}
\hline \multicolumn{4}{|c|}{ Component concentration of test sample 1} & \multicolumn{4}{|c|}{ Component concentration of test sample 2} \\
\hline Name & Molar [\%] & Volume [\%] & Mass $[\%]$ & Name & Molar [\%] & Volume $[\%]$ & Mass $[\%]$ \\
\hline Helium & 0.005483 & 0.005545 & 0.0006828 & Helium & 0.01075 & 0.01086 & 0.001368 \\
\hline Hydrogen & 0.02613 & 0.02643 & 0.00168 & Hydrogen & 0.02908 & 0.02937 & 0.00182 \\
\hline Oxygen & 0.1388 & 0.1402 & 0.1382 & Oxygen & 1.799 & 1.815 & 1.829 \\
\hline $\begin{array}{l}\text { Carbon } \\
\text { dioxide }\end{array}$ & 8.938 & 8.986 & 12.23 & $\begin{array}{l}\text { Carbon } \\
\text { dioxide }\end{array}$ & 8.392 & 8.427 & 11.73 \\
\hline Nitrogen & 2.618 & 2.645 & 2.281 & Nitrogen & 8.982 & 9.065 & 7.993 \\
\hline Methane & 44.11 & 44.50 & 22.01 & Methane & 41.72 & 42.04 & 21.26 \\
\hline Ethane & 11.76 & 11.79 & 11.00 & Ethane & 10.57 & 10.59 & 10.10 \\
\hline Propane & 19.31 & 19.19 & 26.48 & Propane & 16.98 & 16.86 & 23.78 \\
\hline i-Butane & 3.052 & 2.995 & 5.517 & i-Butane & 2.665 & 2.612 & 4.920 \\
\hline n-Butane & 6.098 & 5.968 & 11.02 & n-Butane & 5.328 & 5.208 & 9.838 \\
\hline i-Pentane & 1.661 & 1.600 & 3.728 & i-Pentane & 1.452 & 1.397 & 3.328 \\
\hline n-Pentane & 1.224 & 1.170 & 2.748 & n-Pentane & 1.055 & 1.007 & 2.419 \\
\hline Hexane & 1.060 & 0.9847 & 2.841 & Hexane & 1.020 & 0.9463 & 2.792 \\
\hline
\end{tabular}

Once the dissolved gases were removed from the BFLH (Tab. 4), a stable BFLH with the following percentage of components was obtained:

propane-butane part $-46.0 \%$

pentane-hexane part $-51.8 \%$

diluted gases $-2.2 \%$

Based on the results of the obtained BFLH that appear in Tab. 4, it is also possible to see that when the temperature goes down to $+4^{\circ} \mathrm{C}$, a lot of diluted gases such as methane, ethane, propane, butane are observed in the BFLH. This way, the gas is easily condensed, but at the same time, the BFLH becomes less stable. When the condensation temperature is elevated up to $+20^{\circ} \mathrm{C}$, then heavier fractions are liquefied (pentane, hexane).

The results of the test also demonstrated that the power losses for obtaining fixed volume (100 $\mathrm{ml})$ of the BFLH are similar for both cases, and the deviations are within the measurement error.

Influence of the hydrogen sulfide and carbon dioxide in the OAG on the chemical composition of the BFLH obtained by the compression method.

It is well-known that hydrocarbon gases contain a significant amount of acid gas components - hydrogen sulfide and carbon dioxide ( $\mathrm{CO} 2$ and $\mathrm{H} 2 \mathrm{~S})$, also water vapours. In the presence of acid components, water vapours cause the emergence of active corrosion processes. The availability of hydrogen sulfide and carbon dioxide in the gas composition also increases the content of such water vapours.

The OAG contains this hydrogen sulfide and carbon dioxide, which according to the standards (GOST R 52087-2018) are inadmissible admixtures in combustion gas, and therefore, it becomes necessary to investigate their removal from the BFLH. For these purposes, the OAG is usually purified to extract these acid gases $(\mathrm{CO} 2$ and $\mathrm{H} 2 \mathrm{~S})$ from it, and as a result, the output gas meets the requirements of GOST.

Based upon these facts, several investigations were also realized using the proposed mobile laboratory unit "LURPNG" for determining and analyzing the amount of hydrogen sulfide and carbon dioxide in the BFLH obtained by compression, and this as a consequence of their presence and concentrations in the very initial OAG the BFLH was to be obtained from. The experiments were conducted at two oil fields where the OAG contained a lot of hydrogen sulfide and carbon dioxide so as to be able to draw more robust conclusions on the efficacy of the unit and its working principle and method. The chemical compositions of the inlet gas (OAG) and outlet gas (after processing) are given in Tab. 5. 
Tab. 5. Chemical composition of the inlet gas $(O A G)$ and outlet gas after the BFLH separation

\begin{tabular}{|c|c|c|c|c|}
\hline \multirow{2}{*}{$\begin{array}{l}\text { Component composition, molar fraction, } \\
{[\%] \text { : }}\end{array}$} & \multicolumn{2}{|c|}{ Oil field 1 , test sample 1} & \multicolumn{2}{|c|}{ Oil field 2 , test sample 2} \\
\hline & inlet gas & outlet gas & inlet gas & outlet gas \\
\hline Oxygen & Under 0.0100 & Under 0.0100 & Under 0.0100 & Under 0.0100 \\
\hline Nitrogen & 41.4927 & 47.5814 & 44.1051 & 47.2568 \\
\hline Helium & 0.0633 & 0.0775 & 0.0678 & 0.0746 \\
\hline Hydrogen & 0.0157 & 0.0195 & 0.019 & 0.0173 \\
\hline Hydrogen dioxide & 10.8218 & 12.0546 & 11.5929 & 12.221 \\
\hline Methane & 11.4837 & 13.8878 & 11.8629 & 13.1098 \\
\hline Ethane & 5.4244 & 5.7081 & 6.2227 & 6.3293 \\
\hline Propane & 8.0524 & 7.6568 & 8.6778 & 7.939 \\
\hline i-Butane & 2.6805 & 1.7967 & 2.4952 & 1.9645 \\
\hline n-Butane & 6.4392 & 3.1647 & 5.0647 & 3.6696 \\
\hline neo-Pentane & 0.0124 & 0.004 & 0.008 & 0.0054 \\
\hline i-Pentane & 5.3228 & 1.2818 & 2.6507 & 1.3978 \\
\hline n-Pentane & 3.0656 & 0.7835 & 1.6108 & 0.7057 \\
\hline Hexane & 1.9801 & 0.7188 & 2.347 & 0.4491 \\
\hline Benzene & 0.0326 & 0.0121 & 0.0686 & 0.0096 \\
\hline Heptane & 0.1174 & 0.0505 & 0.3938 & 0.0536 \\
\hline Toluene & 0.0091 & 0.0035 & 0.0016 & 0.0053 \\
\hline Octane & 0.0087 & 0.0097 & 0.0353 & 0.0088 \\
\hline Hydrogen sulfide & 2.9575 & 5.1732 & 2.7581 & 4.7661 \\
\hline Carbonyl sulfide & 0.0057 & 0.0057 & 0.0056 & 0.0056 \\
\hline Methyl mercamptan & 0.0044 & 0.0051 & 0.0049 & 0.006 \\
\hline Ethyl mercamptan & 0.003 & 0.0018 & 0.0025 & 0.0021 \\
\hline Carbon disulfide & 0.0002 & Under 0.0001 & 0.0002 & 0.0002 \\
\hline Propyl mercamptan-2 & 0.0045 & 0.0019 & 0.0027 & 0.0015 \\
\hline 2-Methylpropyl mercamptan-1 & 0.0007 & 0.0005 & 0.0006 & 0.0005 \\
\hline Propyl mercamptan-1 & 0.0004 & 0.0003 & 0.0003 & 0.0002 \\
\hline Methylethylsulfide & 0.0002 & Under 0.0001 & 0.0002 & 0.0002 \\
\hline Butyl mercamptan-2 & 0.0005 & 0.0003 & 0.0005 & 0.0003 \\
\hline Methylpropylsulfide & 0.0001 & Under 0.0001 & 0.0001 & Under 0.0001 \\
\hline Dimethylsulfide & 0.0004 & 0.0002 & 0.0003 & 0.0002 \\
\hline
\end{tabular}

Similarly, Tab. 6 presents the chemical compositions of the BFLH obtained from the OAG (Tab. 5) after being processed at the laboratory unit "LURPNG". The analysis of the results obtained indicates that the presence of hydrogen sulfide in the outlet gas increases after separation (Tab. 5), and the presence of hydrogen sulfide becomes minimal at its solubility level in the BFLH (Tab. 6). The authors also come to the conclusion that the stable liquid fraction of the BFLH is obtained ecologically clean, i.e. purified from hydrogen sulfide and carbon dioxide admixtures, ad this using the designed and developed unit and the proposed compression method.

Tab. 6. BFLH composition (test sample 1, test sample 2)

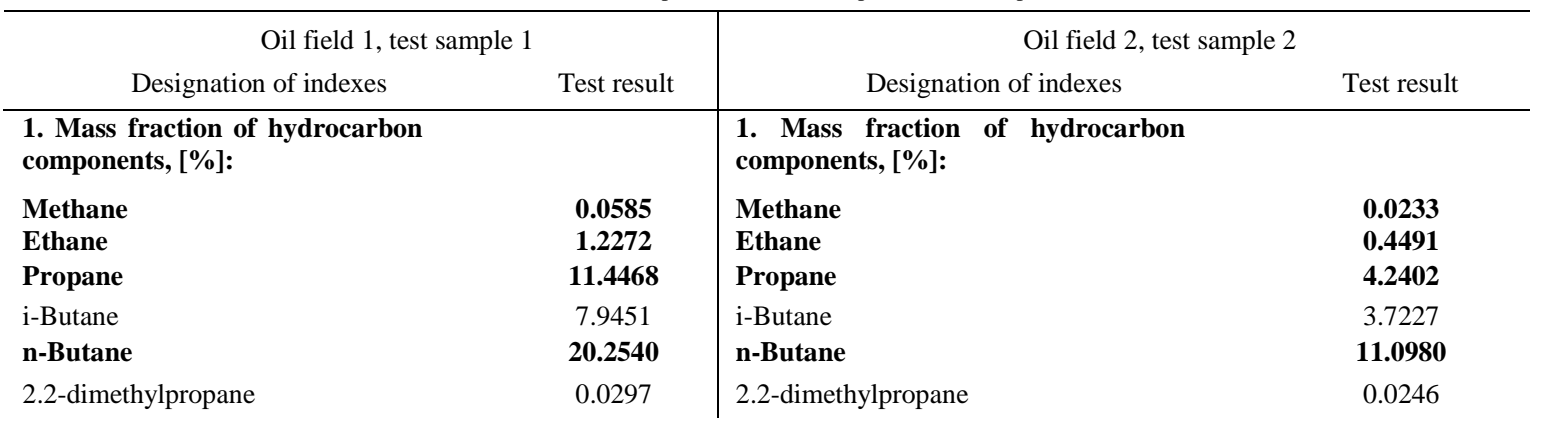




\begin{tabular}{|c|c|c|c|}
\hline Dimethylcyclopropane & 0.0090 & Dimethylcyclopropane & 0.0050 \\
\hline i-Pentane & 16.0666 & i-Pentane & 14.1624 \\
\hline n-Pentane & 10.5830 & n-Pentane & 9.8088 \\
\hline Isomers $\mathrm{C}_{6}$ & 12.8021 & Isomers $\mathrm{C}_{6}$ & 18.5359 \\
\hline Naphtenes $\mathrm{C}_{6}$ & 2.0781 & Naphtenes $\mathrm{C}_{6}$ & 3.4136 \\
\hline n-Hexane & 5.1581 & Hexenes & 0.0006 \\
\hline Benzene & 0.0569 & n-Hexane & 7.5244 \\
\hline Isomers $\mathrm{C}_{7}$ & 3.4676 & Benzene & 0.0600 \\
\hline Naphtenes $\mathrm{C}_{7}$ & 2.0124 & Isomers $\mathrm{C}_{7}$ & 7.8591 \\
\hline n-Heptane & 1.7317 & Naphtenes $\mathrm{C}_{7}$ & 4.0051 \\
\hline Toluene & 0.0571 & n-Heptane & 4.4016 \\
\hline Isomers $\mathrm{C}_{8}$ & 1.1619 & Toluene & 0.0893 \\
\hline Naphtenes $\mathrm{C}_{8}$ & 0.8221 & Isomers $\mathrm{C}_{8}$ & 3.5402 \\
\hline $\begin{array}{l}\text { n-Octane } \\
\text { Aromatic hydrocarbons } \mathrm{C}_{8}\end{array}$ & $\begin{array}{l}\mathbf{0 . 3 9 9 2} \\
0.0556\end{array}$ & $\begin{array}{l}\text { Naphtenes } C_{8} \\
\text { n-Octane }\end{array}$ & $\begin{array}{l}2.2649 \\
\mathbf{1 . 4 2 0 3}\end{array}$ \\
\hline $\begin{array}{l}\text { Isomers } \mathrm{C}_{9} \\
\text { Naphtenes } \mathrm{C}_{9}\end{array}$ & $\begin{array}{l}0.3521 \\
0.1142\end{array}$ & $\begin{array}{l}\text { Aromatic hydrocarbons } \mathrm{C}_{8} \\
\text { Isomers } \mathrm{C}_{9}\end{array}$ & $\begin{array}{l}0.2189 \\
1.2427\end{array}$ \\
\hline n-Nonane & 0.0105 & Naphtenes $C_{9}$ & 0.5460 \\
\hline Aromatic hydrocarbons $\mathrm{C}_{9}$ & 0.0190 & n-Nonane & 0.2841 \\
\hline Isomers $\mathrm{C}_{10}$ & 0.0424 & Aromatic hydrocarbons $\mathrm{C}_{9}$ & 0.0717 \\
\hline Naphtenes $C_{10}$ & 0.0168 & Isomers $\mathrm{C}_{10}$ & 0.1968 \\
\hline $\begin{array}{l}\text { Aromatic hydrocarbons } \mathrm{C}_{10} \\
\text { n-Decane }\end{array}$ & $\begin{array}{l}0.0039 \\
\mathbf{0 . 0 1 0 5}\end{array}$ & $\begin{array}{l}\text { Naphtenes } C_{10} \\
\text { Aromatic hydrocarbons } C_{10}\end{array}$ & $\begin{array}{l}0.0557 \\
0.0137\end{array}$ \\
\hline Isomers $\mathrm{C}_{11}$ & 0.0052 & n-Decane & 0.0303 \\
\hline Naphtenes $\mathrm{C}_{11}$ & 0.0012 & Isomers $\mathrm{C}_{11}$ & 0.0181 \\
\hline n-Undecane & 0.0038 & Naphtenes $\mathrm{C}_{11}$ & 0.0046 \\
\hline n-Dodecane & 0.0016 & Aromatic hydrocarbons $C_{11}$ & 0.0012 \\
\hline Indanes & 0.0003 & n-Undecane & 0.0093 \\
\hline $\begin{array}{l}\text { 2. Mass fraction of carbon } \\
\text { dioxide }\end{array}$ & 0.7661 & Isomers $\mathrm{C}_{12}$ & 0.0005 \\
\hline $\begin{array}{l}\text { 3. Mass fraction of hydrogen } \\
\text { sulfide }\end{array}$ & 1.1799 & Naphtenes $C_{12}$ & 0.0005 \\
\hline $\begin{array}{l}\text { 4. Mass fraction of sulfur } \\
\text { containing components: }\end{array}$ & & Aromatic hydrocarbons $\mathrm{C}_{12}$ & 0.0004 \\
\hline Mercamptans: & & n-Dodecane & 0.0084 \\
\hline Methyl mercamptan & 0.0050 & Indanes & 0.0054 \\
\hline Ethyl mercamptan & 0.0076 & Total of $\mathrm{C}_{13+}$ & 0.0064 \\
\hline Propyl mercamptan-2 & 0.0161 & 2. Mass fraction of carbon dioxide, $\%$ & 0.2899 \\
\hline 2-Methylpropyl mercamptan-2 & 0.0009 & $\begin{array}{l}\text { 3. Mass fraction of hydrogen sulfide, } \\
\%\end{array}$ & 0.2862 \\
\hline Propyl mercamptan-1 & 0.0012 & $\begin{array}{l}\text { 4. Mass fraction of sulfur containing } \\
\text { components, } \% \text { : }\end{array}$ & \\
\hline Butyl mercamptan-2 & 0.0044 & Mercamptans: & \\
\hline 2-Methylpropyl mercamptan-1 & 0.0003 & Methyl mercamptan & 0.0035 \\
\hline Butyl mercamptan-1 & 0.0003 & Ethyl mercamptan & 0.0077 \\
\hline Sulfides: & & Propyl mercamptan-2 & 0.0206 \\
\hline Dimethylsulfide & 0.0007 & 2-Methylpropyl mercamptan-2 & 0.0009 \\
\hline Methylethylsulfide & 0.0007 & Propyl mercamptan-1 & 0.0019 \\
\hline Methylisopropylsulfide & $\begin{array}{l}\text { Less than } \\
0.0001\end{array}$ & Butyl mercamptan-2 & 0.0085 \\
\hline Diethylsulfide & 0.0001 & 2-Methylpropyl mercamptan-1 & 0.0003 \\
\hline Methylpropylsulfide & 0.0007 & Butyl mercamptan-1 & 0.0003 \\
\hline Disulfides: & & Sulfides: & \\
\hline Methylpropylsulfide & 0.0001 & Dimethylsulfide & 0.0008 \\
\hline Methylisopropylsulfide & $\begin{array}{l}\text { Less than } \\
0.0001\end{array}$ & Methylethylsulfide & 0.0005 \\
\hline Diethylsulfide & $\begin{array}{l}\text { Less than } \\
0.0001\end{array}$ & Methylisopropylsulfide & 0.0003 \\
\hline
\end{tabular}




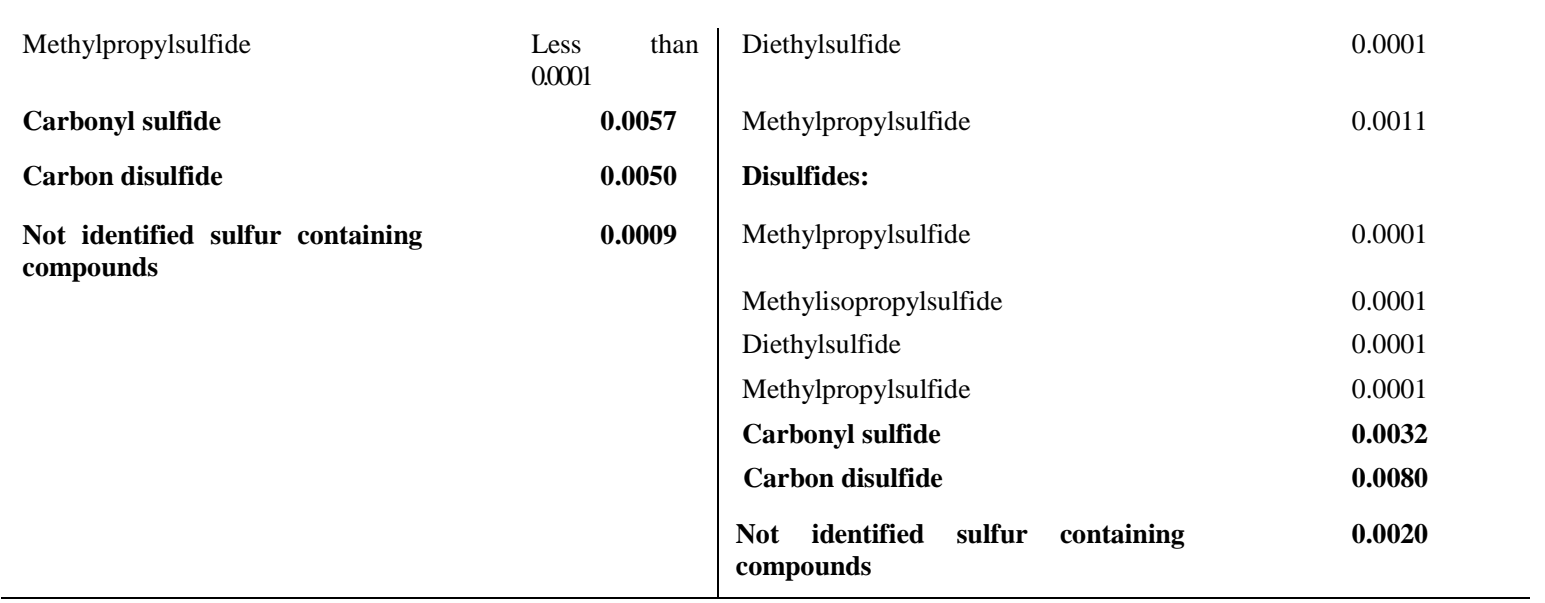

On the other hand, the experiment results obtained and appearing in Tab. 5 and 6 confirm the calculation values of the parameters given in Tab. 1 and that hydrogen sulfide is not condensed within the considered range of temperatures and pressures. Thus, the liquefied gas purified from harmful admixtures (BFLH) is obtained directly on small-rate oil fields with minimum power losses. The method proposed within this paper for the OAG compression separation using a refrigeration machine is new for the units of such type. The method working capacity and efficacy is also proved by the experiments carried out. Both the proposed method of OAG compression separation and the mobile laboratory unit "LURPNG" based on it are recommended for use on distant oil fields with a low rate, for which the pipeline installation is economically impractical and unfeasible. The results of the experiments show that an ecologically clean stable liquid fraction of BFLH purified from hydrogen sulfide and carbon dioxide admixtures is obtained using the proposed method and unit. The resulting product can be further delivered for further treatment to produce petrochemical products, to be pumped into the wells as a solvent for repairs or even to be used as fuel at the oil fields with insufficient amount of own OAG.

\section{Conclusions and Further research}

The present paper presented a mobile laboratory unit named "LURPNG" that allows obtaining the BFLH directly at small-rate faraway oil fields where there are poor or non-existing piping systems and/or are away from major transport infrastructure. These oil fields are characterized by having a low gas factor and caloricity due to high nitrogen content. The presented mobile unit is mainly characterized by its ability to obtain the BFLH using a compression approach or method, which is also a contribution and added value of this paper.

A series of experiments were realized using the proposed mobile unit where it was possible to define optimal modes for the obtention of the BFLH from AOG with different initial compositions of hydrocarbons components and harmful admixtures, such as hydrogen sulfide and carbon dioxide. The study also experimentally confirmed concrete values for the dependence of the OAG compression pressure on the temperature. In this regard, it was possible to conclude that when the condensation temperature goes up, the liquid fraction of the BFLH becomes more stable, since it contains fewer volatile fractions and does not contain the admixtures of hydrogen sulfide and carbon dioxide. On the other hand, it was also demonstrated that at low condensation temperatures the gas solubility increases, subsequently the caloricity of the BFLH liquid fraction goes up, and thus it can be used as fuel for technological purposes at oil fields or to heat technical premises.

The BFLH obtained in the experiments proved to be a valuable power product without hydrogen sulfide admixtures, despite the fact that this was obtained from OAG with high hydrogen sulfide content. Besides, the compression method of OAG separation proposed by the authors allows flexibly obtaining the liquid fraction of the BFLH depending on its further application, i.e. for pumping it into wells as a solvent during maintenance, for the transportation by mobile transport as an ecologically pure fuel. The experiments also allowed obtaining important results related to the quantitative and qualitative composition of the BFLH for certain small-rate oil fields. Future research aims at experimentally examining low oil fields in specific regions in order to determine the presence of wells for which the utilization of the LURPNG mobile laboratory facility is convenient and costeffective in term of OAG utilization. The small size and mobility of the proposed unit will allow these works to be performed for all fields, regardless of their remoteness. 


\section{References}

Arutyunov, V. S.; Savchenko, V. I.; Sedov, V. I.; Nikitin, A. V.; Troshin, K. Y.; Borisov, A. A.; Fokin, I. G.; Makaryan, I. A. and Strekova, L. N. (2017). New Potentialities for Utilization of Associated Petroleum Gases in Power Generation and Chemicals Production. Eurasian Chemico-Technological Journal, 19, pp. 265-271, DOI: http://doi.org/10.18321/ectj662.

Arutyunov, V.; Troshin, K.; Nikitin, A.; Belyaev, A.; Arutyunov, A.; Kiryushin, A. and Strekova, L. (2020). Selective oxycracking of associated petroleum gas into energy fuel in the light of new data on self-ignition delays of methane-alkane compositions. Chemical Engineering Journal, 381, DOI: https://doi.org/10.1016/j.cej.2019.122706.

Atoufi, H. D. and Lampert, D. J. (2020). Impacts of Oil and Gas Production on Contaminant Levels in Sediments. Current Pollution Reports, DOI: https://doi.org/10.1007/s40726-020-00137-5.

Bako, B. and Božek, P. (2016). Trends in simulation and planning of manufacturing companies. Procedia Engineering [online]. Proccedings of the International Conference on Manufacturing Engineering and Materials, ICMEM 2016, 6. - 10. June 2016, Nový Smokovec, Slovakia, 149, pp. 571-575.

Baranov, M. N.; Božek, P.; Prajová, V.; Ivanova, T. N.; Novokshonov, D. N.; Korshunov, A. I. (2017). Constructing and calculating of multistage sucker rod string according to reduced stress. Acta Montanistica Slovaca, 22 (2), pp. 107-115.

Blyablyas, A. N. and Korepanov, M. A. (2017). Technology of compressor-absorption purification as the method of to increase the efficiency of OAG application. Journal Exposition, Oil, Gas, 1 (54).

Braginskii, O. B. and Chernavskii, S.Y. (2010). Utilization of Associated Petroleum Gas: Economic Issues. Rossiiskii Khimicheskii Zhurnal, 54(5), pp. 19-22.

GOST R 52087-2018. Gas and hydrocarbons.

GOST R 55598. Oil-associated gas, classification criteria.

Igitkhanyan, I. A. and Bogak , T. V. (2014). Efficiency of oil-associated gas processing methods in Russia. Bulletin of Tomsk State Pedagogic University, (TSPU Bulletin), 8(149).

Ivanova, T. N.; Korshunov, A. I. and Koretckiy, V. P. (2018). Dual Completion Petroleum Production Engineering for Several Oil Formations. Management Systems in Production Engineering. Gliwice 2018, 26(4), pp. 133-136, DOI: 10.1515/mspe-2018-0035.

Karch, L.; Škvareková, E. and Kawicki A. (2018). Environmental and geological impact assessment within a project of the NorthSouth Gas Interconnections in Central Eastern Europe. Acta Montanistica Slovaca, 23 (1), pp. 26-38.

Kayukova, G.P.; Romanov, G. V.; Lukianova, R.G. and Sharipova. N.S. (2009). Organic geochemistry of sedimentary strata and foundation of Tatarstan territory, M.: GEOS, 487 p., with illustrations.

Khafizov, F.S. and Krasnov, A. V. (2012). Pressure of saturated vapors for oil products. Electronic scientific journal Oil and gas engineering, Iss.3, pp. 406-412.

Kiryushin, P. A.; Knizhnikov, A. Y. ; Kochi, K. V.; Puzanov, T. A. and Uvarov, S.A. (2013). Oil-associated gas in Russia: prohibited to burn, must be processed! Analytical report on economic and ecological expenditures of burning oil-associated gas in Russia. World Wildlife Fund (WWF), Moscow, 2013.

Kuppusamy, S.; Maddela, N. R.; Megharaj, M. and Venkateswarlu, K. (2020). An Overview of Total Petroleum Hydrocarbons. Total Petroleum Hydrocarbons. Springer, Cham, pp. 1-27, DOI: https://doi.org/10.1007/978-3-030-24035-6_1.

Lipanov, A. M.; Yu, A.; Leschev, M. A.; Korepanov, P. G.; Ovcharenko, I. and Zaitsev, N. (2016). Unit for oilassociated gas separation at the oil fields of Udmurt Republic. Proceedings of All-Russian scientificpractical conference dedicated to the 85th anniversary of V.I. Kudinov, Doctor of Science in Engineering, Professor, Academician of RANS "Modern technologies of oil and gas extraction. Perspectives of the development of mineral and raw material complex (Russian and world experience)”, May 26-27, 2016. — Izhevsk: Publishing Center "Udmurt University", pp. 231-236.

Mullakhmetova, L. I. and Cherkasova, E. I. (2015). Oil-associated gas: preparation, transportation and processing. Bulletin of Technological University. 18 (19), pp. 83-90.

Physical encyclopedia (2019) - Normal conditions. Available at: http://femto.com.ua/articles/part_2/2520.html.

Rafa, V.; Borzan, M. and Teuţan, E. (2014). Determination of occurring of sealing damages in transport of hydrocarbons, detection of accidental leakes of natural gases. In: ACTA TECHNICA NAPOCENSIS, Series: Applied Mathematics and Mechanics and Engineering, 57(2), pp.287-290.

RIA Novosti (2019). Oil-associated gases. Available at: https://ria.ru/20100201/206673791.html.

Semenova, S. A. and Abrzhina, L. L. (2016) Methods of decreasing the harmful effect of burning oil-associated gas by its utilization. Available at: http://elar.urfu.ru/bitstream/10995/74233/1/sueb_2016_028.pdf.

Skaftymov, N. A. (2012). Basics of gas supply. Reprinted edition of 1975. — M.: ECOLIT, 2012. — 344 p. 
Škvareková, E.; Tomašková, M.; Wittenberger, G.; Zelenák, Š. (2019). Analysis of Risk Factors for Underground Coal Gasification. Management Systems in Production Engineering. Gliwice 2019, 27(4), pp. 227-235, DOI: $10.1515 / \mathrm{mspe}-2019-0036$.

Speight, J. (2012). Oil analysis. Reference book: translated from English under the editorship of L.G. Nekhamkina, E.A. Novikova. - SPb. - "Profession", 480 p., with illustrations.

Vorobiev, A. E. and Zhang L. (2018). Applied innovative technologies for processing of associated gas in China. The Eurasian Scientific Journal, [online] 2(10). Available at: https://esj.today/PDF/11NZVN218.pdf.

Yu, A.; Leschev, M.; Kurguzkin, G.; Lipanov, A. M.; Yu, S.; Popov, D. Zorin, M. (2009). Device for biogas separation into methane and carbon dioxide. Patent RU (11) 2424478 (13) C2.

Zaitsev, I. N.; Korepanov, M. A.; Leschev, A. Y.; Lipanov, A.M.; Ovcharenko, P. G. (2017). Methods of oilassociated gas separation at the oil field. Industrial and ecological safety, labor protection, Iss.1, pp.20-21. 